\title{
Study Subject Medical Imaging Report
}

National Cancer Institute

\section{Source}

National Cancer Institute. Study Subject Medical Imaging Report. NCI Thesaurus. Code C115511.

Records pertaining to the findings from a study subject's medical imaging results. 